\title{
تصنيف الجامعات: ما لله وما عليه
}

\section{University Ranking: Pros and Cons}

خالا مصطفى Khaled Moustafa Editor of Arabic Science Archive (arabixiv.org) محرر الأرشيف العربي العلمي البريد الإلكتروني: Email: khaled.moustafa@arabixiv.org

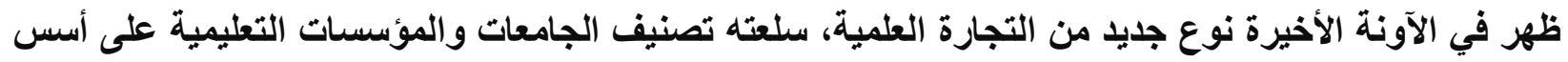

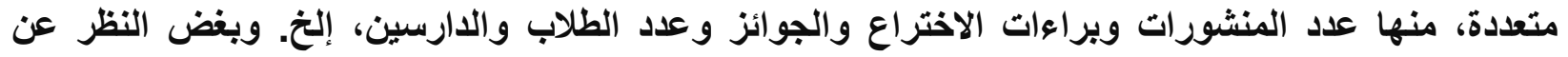

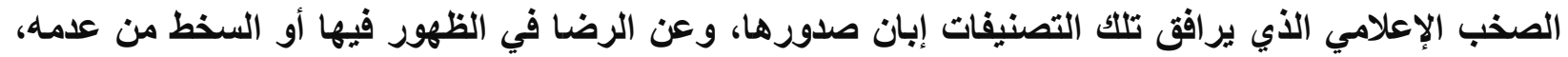
هنايك أسئلة جوهرية ينبغي طرحها، مثل: هل التصاتيف الجامعية جديرة بالاهتمام حقاً؟ وهل تعتمد على المبادئ

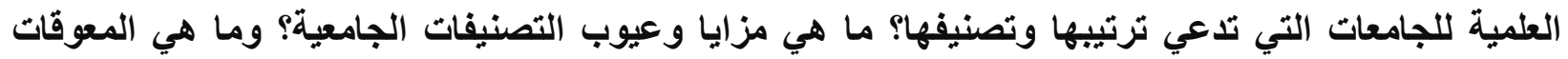

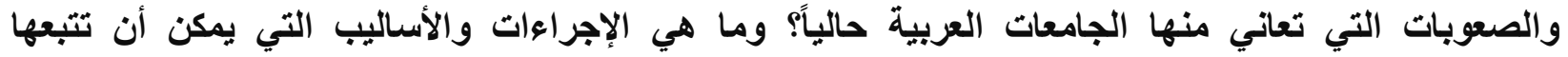

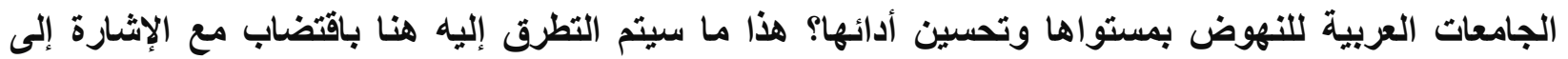

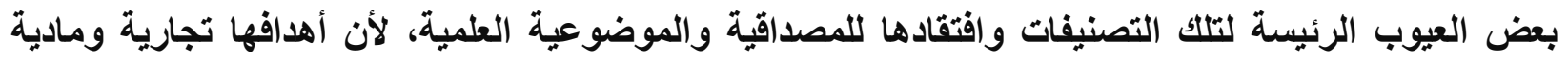

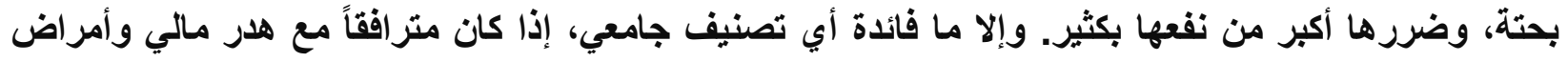

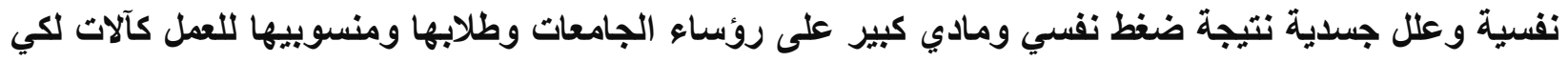

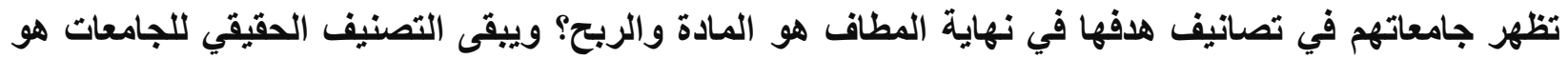

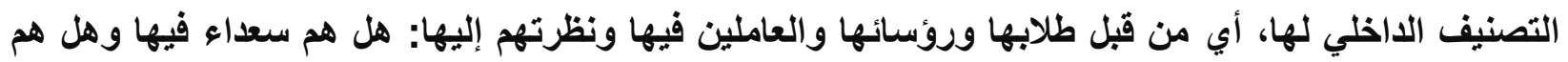

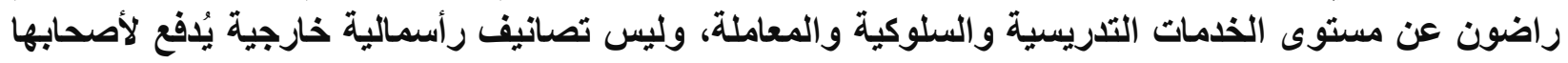

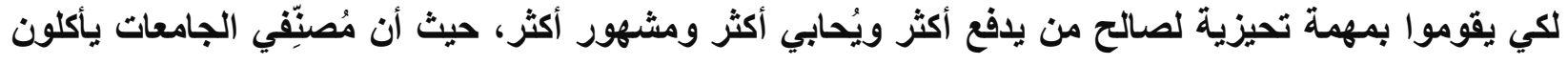

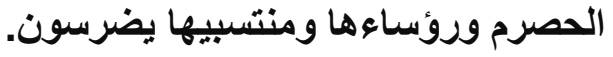

\section{Abstract}

A new type of academic trading has emerged recently around the classification of universities and educational institutions on the basis of a number of characteristics such as the scientific productivity, the number of patents, prizes, students and professors, etc. However, and regardless of the media buzz these classifications create at the time of their publications, and beyond the satisfaction or dissatisfaction of managers whose institutions are classified or not, the question that should be raised on this matter is: are university rankings reliable and valid from scientific and objective viewpoints? Are they based on the scientific rules of the academic institutions they try to rank? These questions will be debated as objectively as possible with a particular focus on some major deficiencies around university ranking. 
Arabic Science Archive (arabixiv.org) | 2018

Keywords: university rankings, university classification, higher education, research institutions, تصنيف الجامعات العربية، ترتيب الجامعات، التعليم العالي في الدول العربية، المؤسسات البحثية في Arabic universities الدول العربية، الجامعات العربية، مساوئ التصنيفات الجامعية، مزايا التصنيفات الجامعية

ظهر أول تصنيف دولي للجامعات، تصنيف شنغهاي، عام 2003 ميلادي ويضم الآن حوالي 1200 جامعة دولية (1)، ثم تلته لاحقاً تصنيفات أخرى متعددة (2)، تعتمد في ظاهرها على معايير كثيرة، منها مثلاً عدد المنشورات العلمية وعدد الطلاب وبراءات الاختراع والجوائز والاكتشافات والمخترعات إلخ. وكان الهدف الأساسي من تصنيف شنغهاي هو مقارنة الجامعات الصينية بنظيراتها الغربية لتشخيص الخلل وتفادي مواضع التقصير في الجامعات الصينية بالنسبة للجامعات الغربية، بتطبيق ما يمكنه تحسين نوعية ومستوى الطلبة والمخرجات العلمية الصينية. ولكن فيما بعد، أصبح التصنيف الجامعي صناعة تجارية بامتياز، ذات أهداف ربحية ومادية تؤثر على اختيار الطلاب للجامعة التي يرغبون الدراسة فيها، وعلى تمويل الجامعات ومشاريع البحث (3) وعلى بيئة العمل وحجم الديون التي تثقل كاهل كثير من الطلاب الذين يستدينون لتحقيق أحلامهم في الدراسة في جامعات مصنفة عالمياً. ومن مساوئ تلك التصنيفات أنها تخلق جواً ضاغطاً نفسياً وجسدياً على رؤساء الجامعات ومنسوبيها وطلابها للعمل ليل نهار للظهور في تلك التصنيفات أو لتحسين مركزها أو على الأقل الحفاظ عليه، وإلا فقد تفقد الجامعة كثير من المزايا وتقل قدرتها على جذب المتميزين والطلبة للدراسة فيها، كما أن بعض الجامعات، عربية أو أجنبية، قد تتبع طرقاً ملتوية وتدفع أموالاً تقل أو تكثر حسب قدرتها التفاوضية والمادية للتعاقد مع "مدرسين مشهورين" أو للتفاوض مع المؤسسات التي تقوم بالتصنيف من أجل رفع رصيدها وسمعتها لتحقيق تلك الغاية دن خلال إنشاء لجان متخصصة وميزانية مكرسة لرفع سوية التصنيف بكل السبل المتاحة، حتى التي تتتهك بعض القواعد المهنية والأخلاقية.

وبغض النظر عن نتائج أي ترتيب جامعي من الناحية المادية والعددية، يُعدّ تصنيف الجامعات من ناحية عملية وعلمية تصنيفاً غير موضوعي ولا علمي، وهو موضع انتقاد من قبل كثير من الهيئات والمؤسسات الدولية، حتى أن بعض رؤساء الجامعات الغربية يرفض المشاركة في إدراج جامعاتهح في تلك التصنيفات التي أثارت ضجة كبيرة وانتقادات واسعة في الأوساط العلمية (4) (5). فهي تعتمد على تصنيف ومقارنة جامعات مختلفة في كل شيء تقريباً، بما في ذلك الموارد المادية والبشرية، وعدد ساعات العمل وتواتره، وعدد العاملين ومؤهلاتهم، ونسبة المدرسين إلى الطلبة، إلخ، ولذلك فهي مقارنات غير صحيحة من وجهة نظر علمية بحتة، والتي تقتضي مقارنة أشياء أو مؤسسات علمية متماثلة في كل شيء، عدا الصفات 
Arabic Science Archive (arabixiv.org) | 2018

المستخدمة للمقارنة (6). ولكن التصنيفات الحالية تقارن جامعات غير قابلة للمقارنة أصلاً، بسبب البون الثاسع بينها في كثير من الأمور ، وإهمال الإنتاج المعرفي بغير اللغة الإنكليزية.

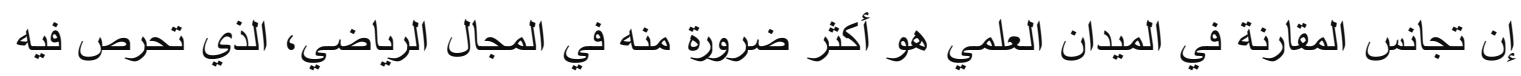
اللجان الرياضية على تنظيم منافسات متكافئة بين المتبارزين، من حيث العدد (كرة السلة مثلاً أو اليد تستلزم وجود نفس العدد من اللاعبين في الفرق المتتافسة)، والوزن (رياضة الملاكمة والمصارعة تستلزم متصارعين

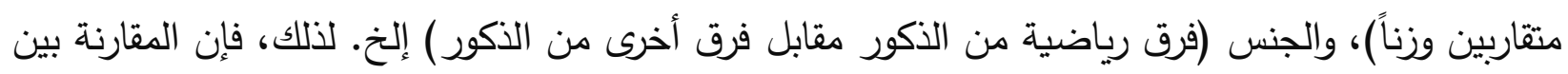

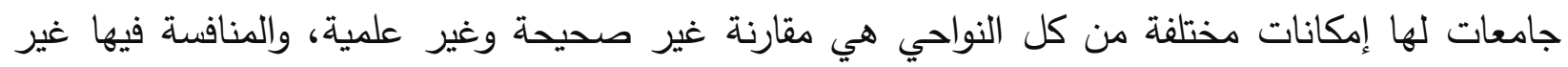

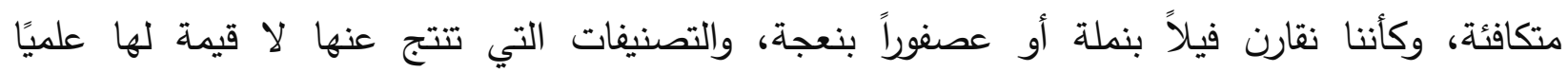
وموضوعيًا، ولكن الصحافة الاستهلاكية، وكثير من المهتمين بالقشور والسطحيات، يجعلون منها صخباً إعلامياً لا مبرر له إلا إحداث ضجنة ولهن في فراغ.

وعلى الرغم من أن بعض الجامعات غير المصنفة قد تتمتع بموارد مالية كبيرة، أحياناً أكبر من جامعات أخرى تحتل مواقعاً متقدمة في بعض التصنيفات، وبغض النظر عن أي تصنيف من الناحية النوعية والإنتاج المعرفي والعلمي، إلا أن كثير من الجامعات لا تزال تعاني من عوائق وحساسيات مهنية

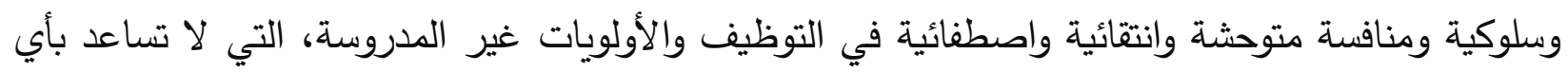

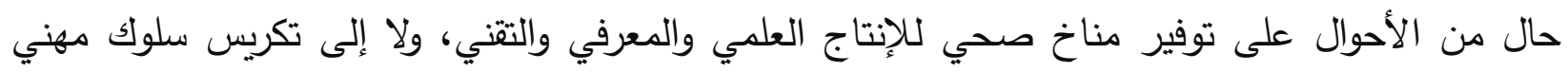
واحترافي يؤطر للعمل الجاد والمثمر لاستتباط حلول مناسبة للمشاكل التي تواجه البلدان التي توجد فيها تلكيك

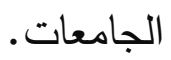

وهناك أسباب عديدة ومظاهر كثيرة لضعف الجامعات على مختلف المستويات، منها على سبيل المثال لا

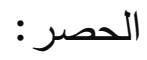
- غياب رؤية علمية واضحة تعتمد على الاهتمامات المحلية والكوادر المؤهلة للعمل على مشاريع تهم

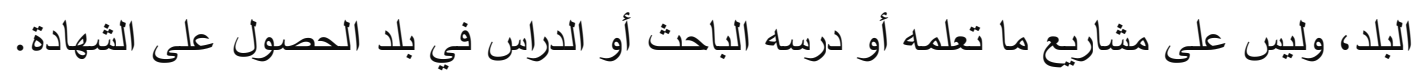

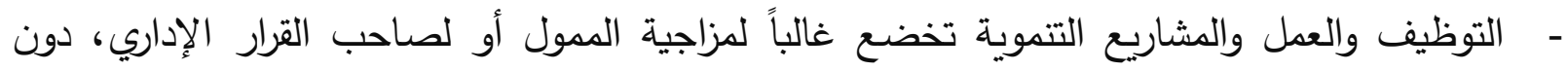
الأخذ بالاعتبار رأي الدارس المعني أو حيثات التطبيق أو التنفيذ أو رأي القائم بالعمل ومدى مطابقته وإمكانية إنجازه في فترة معينة من الزمن. - - سوء التخطيط والرغبة في الحصول على نتائج سريعة في أقصر وقت ممكن، ويأس كثير من الدارسين وهجرهم للبحث والتمحيص والتأليف العلمي. 
- الفساد وضياع الأولويات وانتشار الرِّشا (جمع رشوة) والوساطة في توظيف الثخص غير المناسب في

المكان غير المناسب في الوقت غير المناسب. وهذه الأساليب تسبب أضراراً علمية ومجتمعية كبيرة

- اللامبالاة والسطحية وعدم الثقة بالنفس إلى درجة استيراد كل شيء، بما في ذلك المناهج والأساتذة

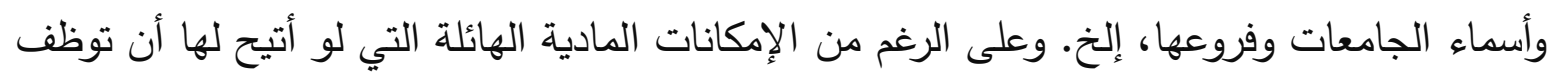
في الاتجاه الصحيح وبتخطيط مناسب، لتبوأت كثير من الجامعات مراكز مرموقة من حيث الإندات الجودة والثفافية والفعالية، وليس من حيث الظهور في تصنيف عبثي هنا أو هناك. كما أن استيراد المعرفة كلياً بدلاً من إنتاجها محلياً يبدو كباقة مزركثة وخداعة أو كسراب يبشّر بالكثير وينتج القليل (10).

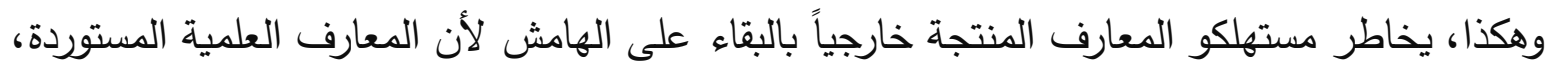
مثلها مثل المنتجات الاستهلاكية، تصبح قديمة وقليلة الفعالية عندما تتوفر منتجات أخرى بديلة،

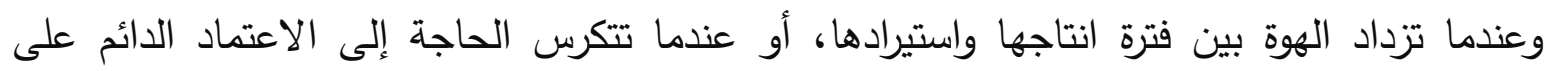

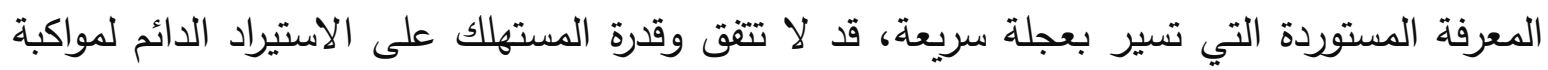

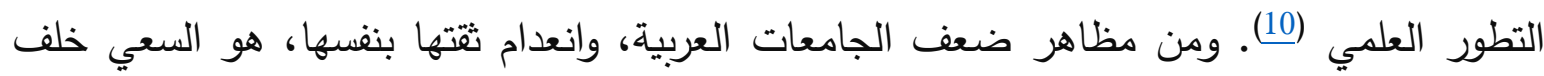
"الاعتماد الأكاديمي" (accreditation) من قبل جامعة خارجية، لكي تظهر بمظهر جامعة معتمدة

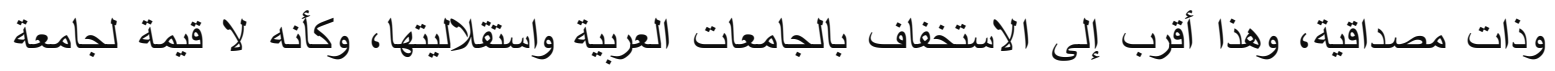
عربية بدون تزكية أجنبية. ولا يوجد أي جامعة غربية تأخذ "شهادة اعتماد" من جامعة عربية أو يابانية

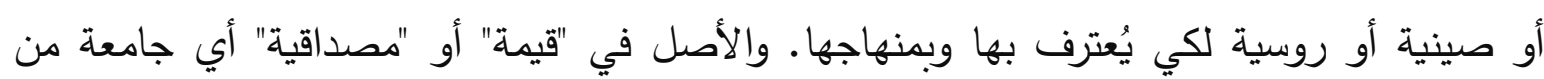

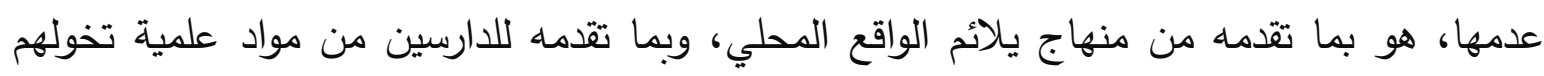

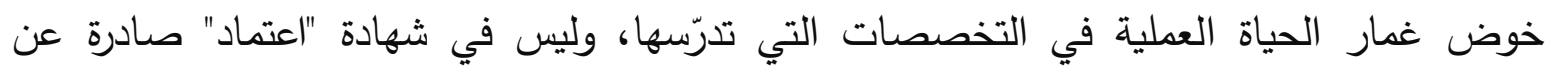
جامعة خارجية، تختلف ظروفها ولغتها عن ظروف الجامعة المحلية.

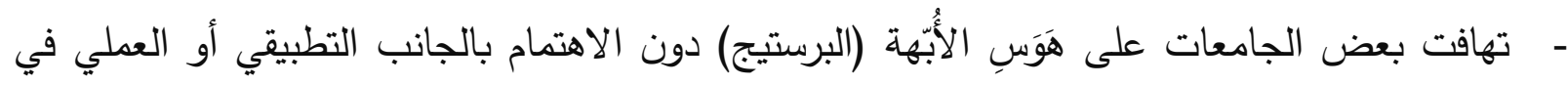

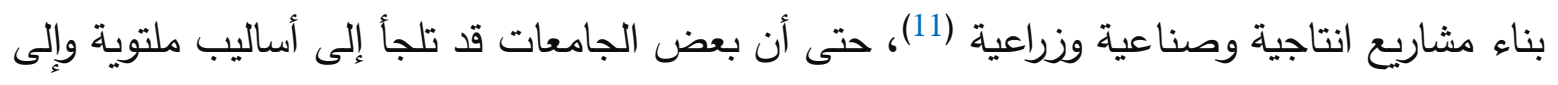
التعاقد مع باحثين أجانب ودفع أموال طائلة من أجل التباهي والمشاركة في نشر مقالة هنا أو هناك، لتاكية

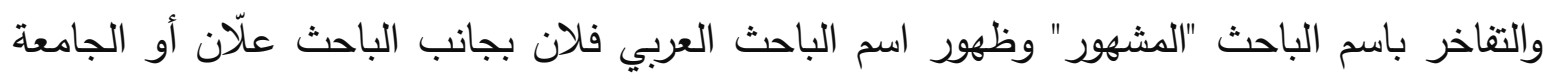
العربية الفُلانية مع الجامعة الأجنبية العَلِّنية. الحساسيات المهنية والأنانية الفردية بين الأقران والزملاء باتجاه تقزيم كل طرف الطية الطرف الآخر ، والنيل

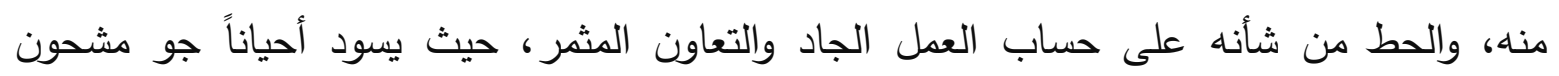


بالأنانية والفوقية ومحاولة تغليب المصلحة الثخصية على المصلحة العامة. وفي بعض الأحيان، يرى بعض المسؤولين والجامعيين في زملائهم أنداداً، وربما أعداءً لهم ولمكانتهم فيحاولون بشتى الوسائل

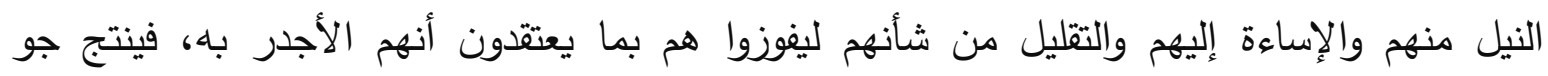

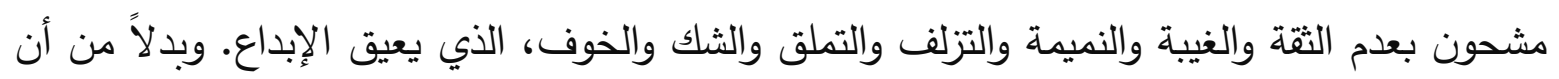

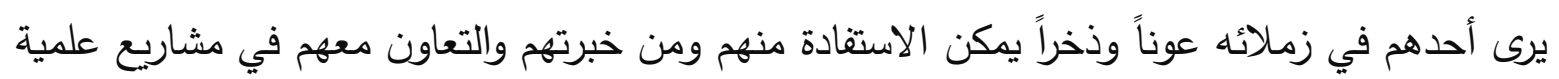

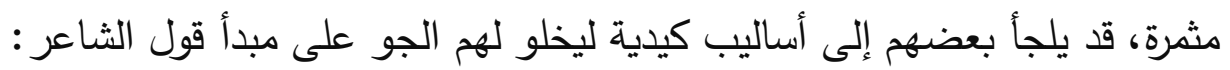

$$
\text { خلا لك الجو فبيضي واصفري ونقّري ما شئت أن تتقّري }
$$

ولكي تحتل الجامعات العربية مراكزاً مقبولة من حيث النوعية العلمية والمهنية، وتحقق نجاحات تجعلها موضع ثقة الناس والمجتمع بها، وليس من أجل الظهور في تصنيفات رأسمالية بحتة، لا بد من معالجة

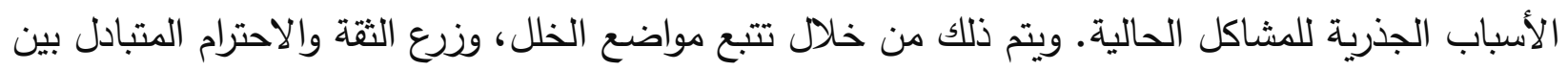

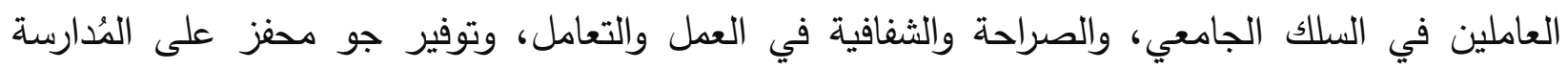

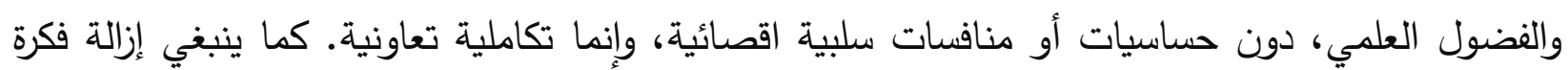
التصنيف الجامعي من الغايات العلمية، وعدم جعلها هوساً وهدفاً بحد ذاته، لأن أهداف التصنيف الجامعي دئية

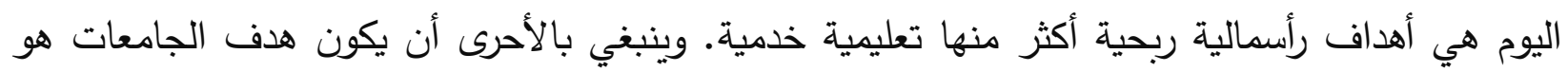

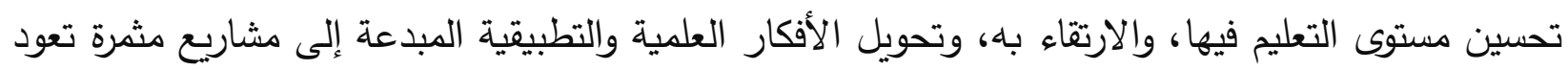

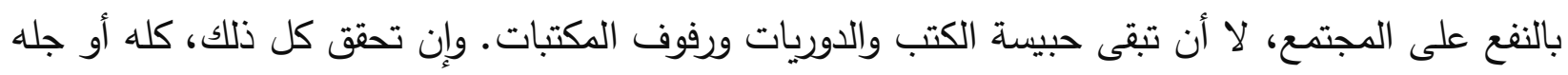
على الأقل، فإن "التصنيف" أو النوعية الجيدة ستكون تحصيل حاصل. ولم يكن هدف الجامعات الغربية الكبيرة، التي تحتل الآن مراكزاً متقدمة في التصنيفات الحالية، هو التصنيف بحد ذاته، وإنما تأمين خدمات تعليمية ومنهجية ودراسية جيدة، تزود الخريجين بمعرفة علمية وعملية تجعل من السهل الثروع في برامج حقيقية تكرس المنهج العلمي لإيجاد حلول علمية ناجعة للمشاكل العالقة. كما ينبغي تثجيع التعليم المستمر ، مدى الحياة، وفتح أبواب الجامعات لكل من يرغب لإنب بمتابعة تعليمه أو تغيير اختصاصه بغض النظر عن العمر أو الغنى أو الفقر ، والمساواة في الرواتب والمزايا المادية والمهنية بين التخصصات، لكيلا تكون هناك مفاضلة أو تمايز على أساس اجتماعي أو مادي يؤدي إلى تهافت إنى

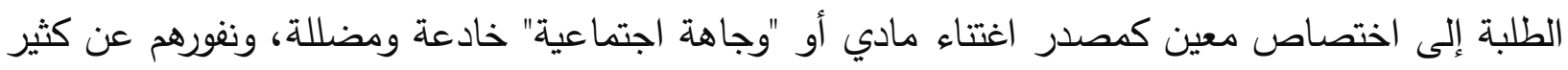
من التخصصات الأخرى المهمة بسبب ضعف مردودها المادي أو "مكانتها الاجتماعية". فمن يختار تخصصه عن رغبة واهتمام سيبدع فيه أكثر ممن يختاره طمعاً في منصب أو جاه أو مال، فيساهم في رفع 
سوية الجامعة أو المؤسسة التي يعمل فيها أكثر ممن يعمل لجني المال والجاه، لأن اهتمام الأخير سيتركز

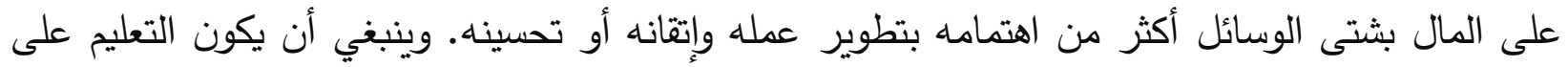

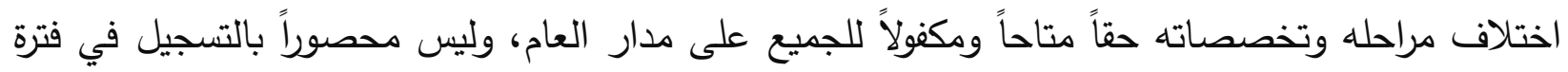
مؤقتة من السنة فقط، ويتم ذلك باعتماد أنظمة النقاط، ولذلك لا يَهُمٌ متى يلتحق الطالب بالجامعة خلال السنة، وإنما بحصوله على عدد النقاط الضرورية التي تخوله الحصول على الثهادة المرغوبة، وألّا يكون التعليم مِنَّة أو تفضلاً أو خاضعاً لأمزجة إدارية أو اعتبارات مالية أو وجاهية، لأن كل المهن في نهاية المطاف قابلة للتعلّم من قبل معظم البشر ، وليس هناك فضل لمهنة على أخرى أو لتخصص على على آخر إلا إلا

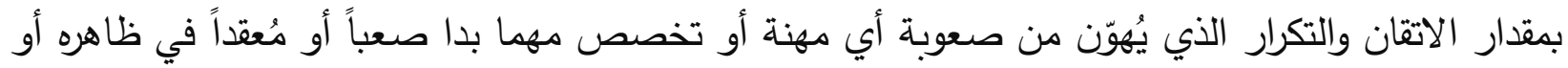
في بدايته. فالمهندس ليس أفضل من المُعلمّم والطبيب ليس أفضل من المهندس، والمحامي ليس أفضل من

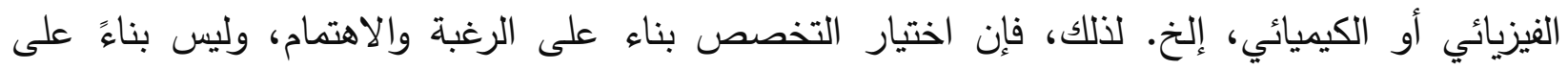
النتيجة المادية أو الاجتماعية المتوخاة، هو أحد أهم ركائز الإبداع والإتقان لتحقيق أفضل النتائج العلمية. ولا بد من توجيه الاهتمام العلمي إلى التعاون بدل التتافس المتوحش عديم الضوابط، وإلى المعاملة الحسنة

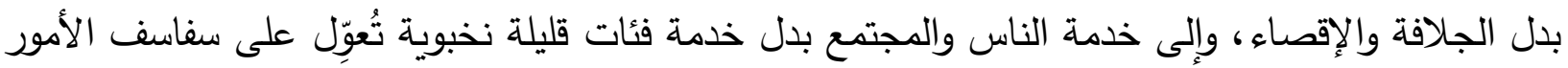
أكثر من جوهرها، من أجل الظهور في تصنيف عبثي لا يفيد في نهاية المطاف إلا الجامعات الرأسمالية،

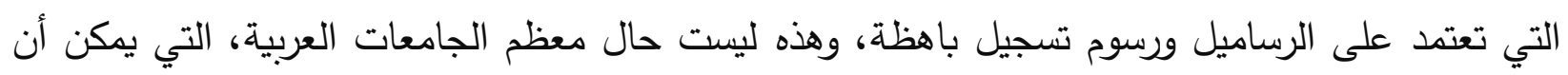
تحتفظ بخصوصيتها في مجانية التعليم، وهي ميزة إيجابية ومجتمعية كبيرة. ولكن بنفس الوقت عليها أن وهن تسعى حثيثاً نحو تحسين جودة التعليم، وتخريج طلبة أكفاء مزودين بالعلم والمعرفة والخبرة الضرورية لإيجاد ولئه

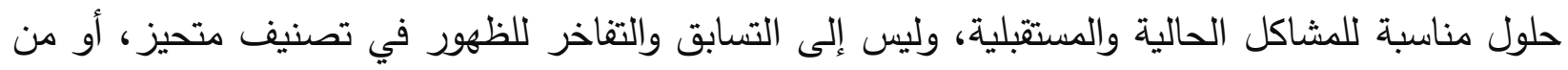
أجل شهرة خادعة ومضللة، لأن ضرر هذه التصنيفات أكبر من نفعها، من وجهة نظر على علية ولفية عادلة

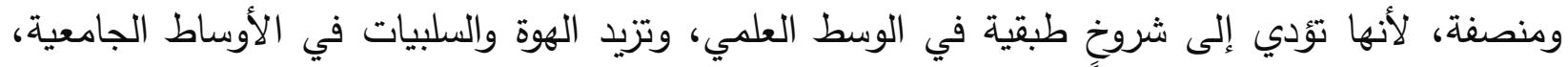
وتؤدي إلى خلق بيئة عمل غير صحية مشوبة بالضغط النفسي والإداري على رئيس الجامعة، وعلى العاملين

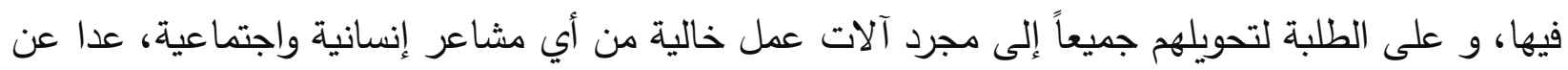
كونها تصنيفات غير موضوعية، ولا تستند إلى مقاربة علمية صحيحة في المقارنة بين مؤسسات غير قابلة للمقارنة أصلاً.

ولو أن الأموال الطائلة التي تُهر على التصنيفات الجامعية- بشكل مباشر أو غير مباشر (رِشَا وحفلات ومفاوضات ومساومات مالية لإغراء "مشهورين" وتوظيف معلنين وإغواء مؤسسات التصنيف بمبالغ كبيرة

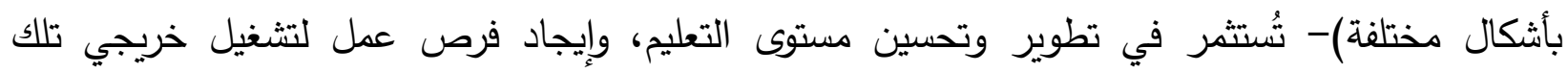


الجامعات، لكان أفضل للمجتمع وللجامعات وللطلاب الذين تخرجه، بدل السعي خلف تصانيف مادية هدفها الربح والتجارة بأساليب جشعة وغير موضوعية أكثر من نشر العلم والمعرفة.

ويبقى التصنيف الحقيقي للجامعات هو التصنيف الداخلي لها، من قبل منسوبيها وإدارييها وطلابها، أي

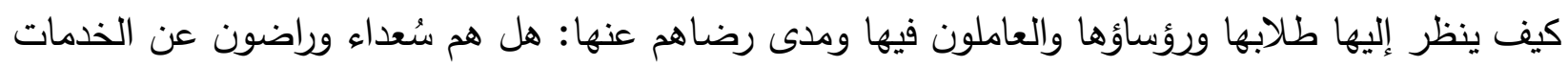
التي تقدمها جامعاتهم للتعلم والتدريس ونوع المعاملة والسلوك إلخ، وليس تصانيف خارجية رأسمالية يُدفع

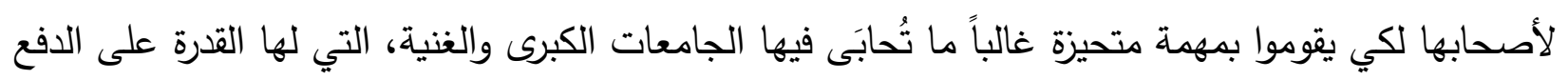

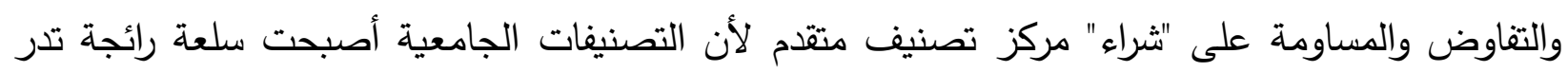

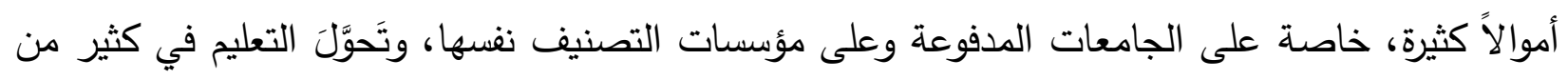
الجامعات إلى تجارة ومرابحة بكل الأساليب والطرق، المشروعة وغير المشروعة، فيدفع الطلاب والعاملون

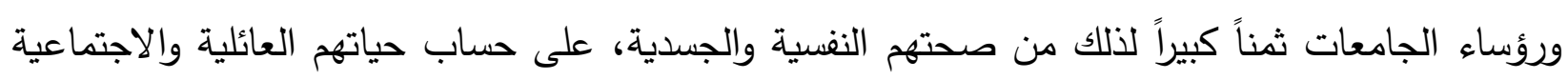
نتيجة الهوس والقلق والحرص على الظهور في تصنيف جامعي لكي لا يفقدوا مناصبهم والمزايا المادية

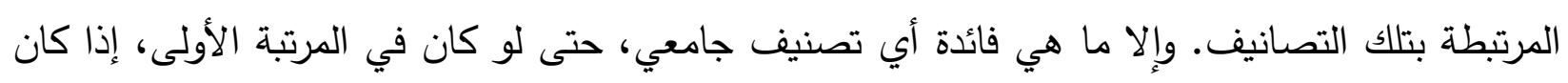

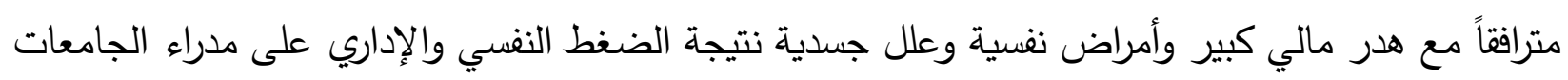

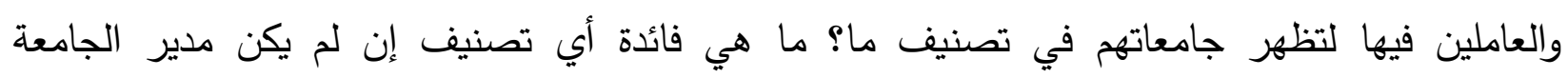
ومرؤوسيه والطلاب سُعداء وراضين عن مستوى الخدمات الجامعية والتدريسية ولم يتعلم الطلاب ما يستفيدون

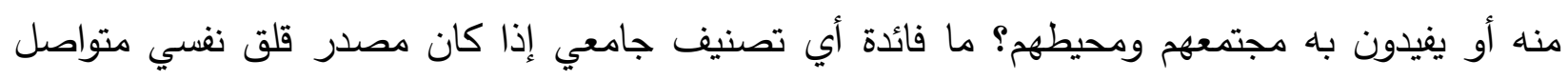

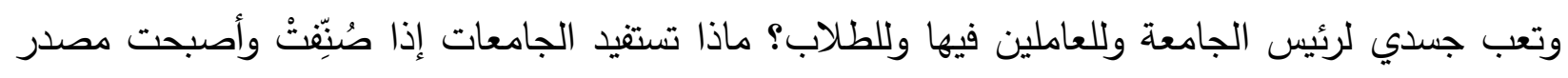

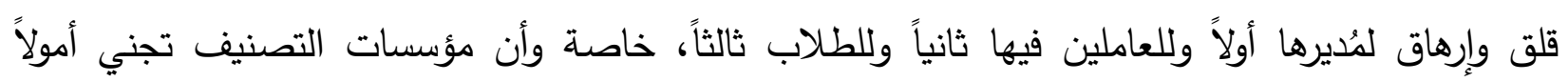

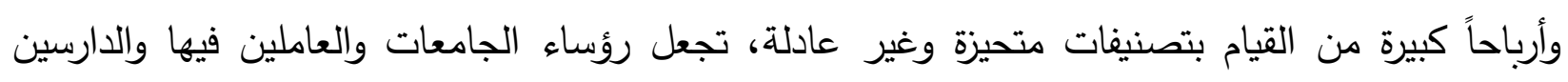

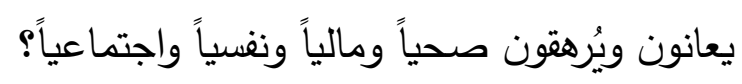

أخيراً، لا بد من الإثارة إلى أن كلمات "بعض" أو "كثير" فيما ذكر أعلاه لا تعني الكل، بل لا يزال هناك

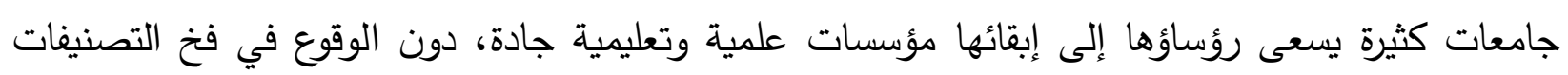

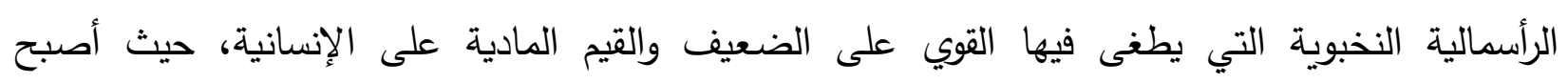
التصنيف الجامعي هوساً وداءً يَنُر في الوسط العلمي في كثير من البلدان، عربية وأجنبية، ويوشك أن الن النية

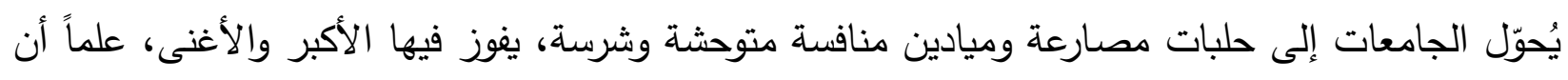
الجامعات قد نشأت وتطورت على مدى قرون سابقة، وساهمت في التثقيف ونشر المعرفة والعلم، دون وجود

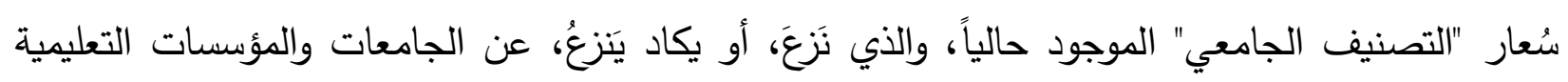


مهنها الحقيقية في بناء مجتمعات إنسانية مُتعلمة ومتعاطفة ومتراحمة لا تكون فيها المادة والأرباح والقيم

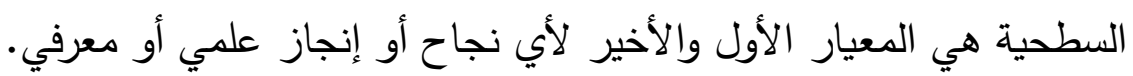

ويمكن تلخيص مساوئ التصنيفات الجامعية بما يلي: "يُصنِفُو الجامعات يأكلون الحصرم ورؤساؤها وطلابها

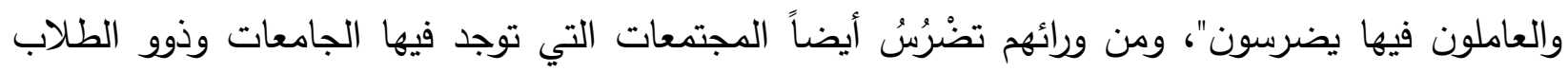

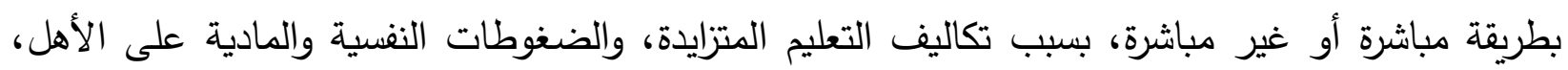
وخصخصة التعليم ونزعته التجارية المتصاعدة في شتى التخصصات.

\section{References}

1. Academic Ranking of World University (ARWU). 20 January 2018; Available from: http://www.shanghairanking.com/aboutarwu.html.

2. Charon, A. and J.P. Wauters, University ranking: a new tool for the evaluation of higher education in Europe. Nephrol Dial Transplant, 2008. 23(1): p. 62-4. DOI: 10.1093/ndt/gfm 279.

3. de Souto Barreto, P., University rankings could bias funding. Science, 2013. 339(6125): p. 12745. DOI: 10.1126/science.339.6125.1274-c.

4. Bookstein, F.L., H. Seidler, M. Fieder, and G. Winckler, Too much noise in the Times Higher Education rankings. Scientometrics, 2010. 85(1): p. 295-299. DOI: 10.1007/s11192-010-0189-5.

5. Butler, D., Academics strike back at spurious rankings. Nature, 2007. 447(7144): p. 514-5. DOI: 10.1038/447514b.

6. Moustafa, K., The disaster of the impact factor. Sci Eng Ethics, 2015. 21(1): p. 139-42. DOI: 10.1007/s11948-014-9517-0.

7. Mohamed, A.A. and M.S. Mohamad, The effect of wasta on perceived competence and morality in Egypt. Cross Cultural Management :An International Journal, 2011. 18(4): p. 412-425.

8. Smith, P.B., H.J. Huang, C. Harb, and C. Torres, How distinctive are indigenous ways of achieving influence? A comparative study of guanxi, wasta, jeitinho, and "pulling strings". Journal of CrossCultural Psychology, 2012. 43(1): p. 135-150.

9. Smith, P.B., C. Torres, C.-H. Leong, P. Budhwar, M. Achoui, and N. Lebedeva, Are indigenous approaches to achieving influence in business organizations distinctive? A comparative study of guanxi, wasta, jeitinho, svyazi and pulling strings. The International Journal of Human Resource Management, 2012. 23(2): p. 333-348. DOI: 10.1080/09585192.2011.561232.

10. Donn, G. and Y. Al Manthri. Education in the Broader Middle East: borrowing a baroque arsenal. 2013. Symposium Books Ltd.

11. Moustafa, K. Promoting an academic culture in the Arab world. Avicenna journal of medicine, 2018, vol. 8, no 3, p. 120. DOI: 10.4103/ajm.AJM_166_17 